Proc. Indian Acad. Sci., Vol. 86 A, No. 5, November 1977, pp. 471-477, (C) Printed in India.

\title{
Coordination properties of vic-isonitrosoimines in their copper (II) and palladium (II) complexes
}

\author{
B P SUDHA, N S DIXIT and C C PATEL \\ Department of Inorganic and Physical Chemistry, Indian Institute of Science, \\ Bangalore 560012
}

MS received 30 July 1977

\begin{abstract}
Preparation and structural characterization of palladium (II) complexes of ligands III-V and copper (II) complexes of III are reported. The elemental analyses of the complexes show that the metal: ligand ratio is $1: 2$. The electrical conductance in acetone shows the non-electrolytic nature of the complexes. The diamagnetic character suggests a gross square-planar geometry for the palladium (II) complexes. Copper (II) complexes are paramagnetic with $\mu_{\text {eff. }} \sim 1.90$ B.M. Spectral data suggest that in all the complexes the ligand coordinates to the metal (II) symmetrically through isonitroso-nitrogen and imine-nitrogen, forming a five membered chelate ring. Amine-exchange reactions of the complexes are discussed and compared on the basis of their structures.
\end{abstract}

Keywords. Vic-isonitrosoimines; ambidentate; amine-exchange.

\section{Introduction}

Recently, considerable interest has been evinced in the coordination chemistry of isonitroso- $\beta$-ketoimines, for the isonitroso group ( $>\mathrm{C}=\mathrm{NOH}$ ) of these ligands can function ambidentately forming coordination compounds having unusual structures. Nickel(II), for example, reacts with isonitrosoacetylacetoneimine(HIAI) forming an orange red diamagnetic complex for which structure $I\left(X=\mathrm{CH}_{3}, \mathrm{R}=\mathrm{H}\right)$ has been assigned (Lacey et al 1970; Bose 1970). The hybrid ring structure is retained when $\mathrm{X}$ is substituted by $\mathrm{OCH}_{3}, \mathrm{OC}_{2} \mathrm{H}_{5}, \mathrm{C}_{6} \mathrm{H}_{5}$ or $\mathrm{NHC}_{6} \mathrm{H}_{5}$ (Iyengar 1975). Further, the $\mathrm{Ni}(\mathrm{II})$ complexes of I react with primary aliphatic amines producing the mono-alkyl

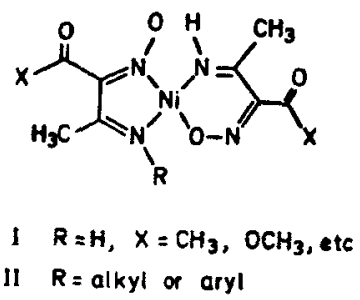

complexes having the same asymmetric structure II $(R=$ alkyl) (Bose 1970; Iyengar et al 1975; Iyengar 1975). The novel structure of this type has been confirmed by $\mathrm{x}$-ray single crystal analysis for the molecule II ( $\left.\mathrm{X}=\mathrm{R}=\mathrm{CH}_{3}\right)$ (McConnel et al 1973). However, studies involving the coordination compounds of isonitroso- $\beta$-ketoimines 
Table 1*

\begin{tabular}{|c|c|c|c|}
\hline Ligand & $\mathrm{M}(\mathrm{II})$ & $\mathbf{R}$ & Abbrev. \\
\hline III & $\mathrm{Cu}$ & $\mathbf{H}$ & $\mathrm{CuL}_{2}$ \\
\hline III & Pd & $\mathbf{H}$ & $\mathrm{PdL}_{2}$ \\
\hline III & $\mathrm{Cu}$ & $\begin{array}{c}\mathrm{CH}_{3}, \mathrm{C}_{2} \mathrm{H}_{5}, n-\mathrm{C}_{3} \mathrm{H}_{7}, n-\mathrm{C}_{4} \mathrm{H}_{9} \\
n-\mathrm{C}_{6} \mathrm{H}_{11}, \mathrm{C}_{6} \mathrm{H}_{5} \mathrm{CH}_{2}\end{array}$ & $\mathrm{Cu}(\mathbf{R}-\mathbf{L})_{\mathbf{2}}$ \\
\hline III & $\mathbf{P d}$ & $\begin{array}{l}\mathrm{CH}_{3}, \mathrm{C}_{2} \mathrm{H}_{5}, n-\mathrm{C}_{3} \mathrm{H}_{7}, i-\mathrm{C}_{3} \mathrm{H}_{7} \\
n-\mathrm{C}_{4} \mathrm{H}_{9}, i-\mathrm{C}_{4} \mathrm{H}_{9}, t-\mathrm{C}_{4} \mathrm{H}_{8} \\
n-\mathrm{C}_{6} \mathrm{H}_{11}, \mathrm{C}_{6} \mathrm{H}_{5} \mathrm{CH}_{3}\end{array}$ & $\operatorname{Pd}(\mathrm{R}-\mathrm{L})_{\mathbf{2}}$ \\
\hline IV, V & $\mathbf{P d}$ & $\mathbf{H}$ & $\mathbf{P d L}_{2}$ \\
\hline IV, V & $\mathbf{P d}$ & $\begin{array}{c}\mathrm{CH}_{3}, \mathrm{C}_{2} \mathrm{H}_{5}, n-\mathrm{C}_{3} \mathrm{H}_{7}, \\
i-\mathrm{C}_{3} \mathrm{H}_{7}, n-\mathrm{C}_{4} \mathrm{H}_{9}\end{array}$ & $\operatorname{Pd}(\mathrm{R}-\mathrm{L})_{2}$ \\
\hline
\end{tabular}

*The elemental analyses of the complexes show metal to ligand ratio to be $1: 2$.

ligands with other transition metals are meagre (Bose et al 1973; Dixit et al 1976). The present paper reports preparation and characterization of $\mathrm{Cu}$ (II) and $\mathrm{Pd}(\mathrm{II})$ complexes of ligands III, IV and V. The amine-exchange reactions of the complexes when $\mathrm{R}=\mathrm{H}$ are discussed and compared on the basis of the proposed structure.

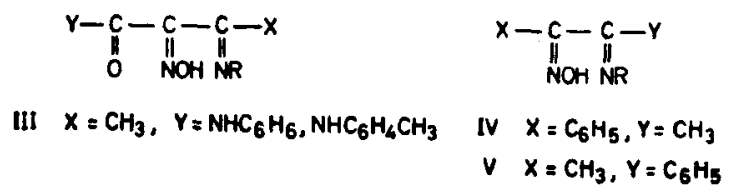

Table 1 lists the complexes prepared and the abbreviations mentioned therein are used throughout the text.

\section{Experimental}

\subsection{Materials and physical measurements}

Isonitrosoacetoacetanilide (Knorr 1887), isonitrosoacetoacet-p-toludide (Knorr 1887), isonitrosobenzylmethylketone (Kolb 1896) and isonitrosopropiophenone (Hartung and Crossly 1943) were prepared by the reported methods. Copper(II) acetate monohydrate (AR) and palladium (II) chloride (Johnson-Mathey) were used as such. Liquor ammonia (LR, density, $0.88 \mathrm{~g} / \mathrm{ml}$ ), methylamine (33\% aq.), ethylamine $(50 \%$ aq.), $n$-propylamine, iso-propylamine, $n$-butylamine, iso-butylamine, tert-butylamine, $n$-hexylamine and benzylamine (all Riedel products) were used. Organic solvents were of Analar grade.

The conductivity of the complexes in acetone was determined with a Siemens conductivity bridge. Molecular weights of the complexes were determined by mass spectroscopy using Atlas Mat Breman Massen spectrometer CH4. Magnetic moments of the complexes were determined at room temperature by Gouy method 
using $\mathrm{Hg}\left[\mathrm{Co}(\mathrm{NCS})_{4}\right]$ as a calibrant. IR spectra in Nujol mull were recorded on a Carl-Zeiss UR-10 spectrometer. Pmr spectra of the palladium(II) complexes in $\mathrm{CDCl}_{3}$ were taken on Varian T-60 and HA-100 spectrometers using TMS as an internal standard. Nitrogen is $\mathrm{x}$-ray photoelectron spectra of a few palladium(II) complexes were recorded on a MeCpherson ESCA-36 photoelectron spectrometer, using aluminium $K_{a}$ x-ray $(h \nu=1486 \mathrm{eV})$ for the photoelectron excitation.

2.1.1. Preparation of complexes: $A$ ll the $\mathrm{Cu}(\mathrm{II})$ and $\mathrm{Pd}(\mathrm{II})$ complexes listed in table 1 were prepared by a general procedure. According to this method, the required ligand was synthesised in situ by the reaction of vic-isonitroso ligand with an appropriate amine and the ligand was then complexed to the metal ion. In a typical procedure, a mixture of isonitrosoacetoacetanilide $(0.002$ mole $)$ and ammonia $(\sim 3 \mathrm{ml})$ in methanol $(30 \mathrm{ml})$ was stirred for about $20 \mathrm{~min}$. To the resulting dark red solution, copper acetate monohydrate (0.001 mole) dissolved in the same solvent was added and the solution was stirred continuously for $4 \mathrm{hrs.} \mathrm{A} \mathrm{crystalline} \mathrm{product} \mathrm{formed} \mathrm{was}$ filtered, washed with methanol and recrystallized from chloroform. Yield, $90 \%$.

2.1.2. Amine-exchange reactions: (a) Reactions of $\mathrm{PdL}_{2}$ ( $\mathrm{L}=\mathrm{IANI}$ or IAPI) with R-NH $\mathrm{NH}_{2}$, where $\mathrm{R}=\mathrm{CH}_{3}, \mathrm{C}_{2} \mathrm{H}_{5}, n-\mathrm{C}_{3} \mathrm{H}_{7}, i-\mathrm{C}_{3} \mathrm{H}_{7}$ or $n-\mathrm{C}_{4} \mathrm{H}_{9}-\mathrm{A}$ suspension of $\mathrm{PdL}_{2}$ $(0.001 \mathrm{~mole})$ in $50 \mathrm{ml}$ chloroform-methanol mixture $(1: 1 \mathrm{v} / \mathrm{v})$ or iso-propanol $(30 \mathrm{ml})$ was treated with an appropriate amine $(3-6 \mathrm{ml})$. The reaction mixture was refluxed over a water bath when the suspension slowly dissolved giving a clear yellow solution. The solution was then partially evaporated in vacuum when yellow crystals of the complexes $(80-90 \%)$ were obtained. The time required for the completion of the reaction in chloroform-methanol mixture when $\mathrm{R}=\mathrm{CH}_{3}, \mathrm{C}_{2} \mathrm{H}_{5}, n-\mathrm{C}_{3} \mathrm{H}_{7}, i-\mathrm{C}_{3} \mathrm{H}_{7}$ and $n-\mathrm{C}_{4} \mathrm{H}_{9}$, was in the sequence of $10-12,8-9 \cdot 5,5-6,4-4.5$ and $3-3.5 \mathrm{hr}$., respectively. The reaction times were 2-3 folds less in iso-propanol.

(b) Reactions of $\mathrm{PdL}_{2}$ (L=IPI, IBMI) with $\mathrm{R}-\mathrm{NH}_{2}\left(\mathrm{R}=\mathrm{CH}_{3}, \mathrm{C}_{2} \mathrm{H}_{5}, n-\mathrm{C}_{3} \mathrm{H}_{7}\right.$ $i-\mathrm{C}_{3} \mathrm{H}_{7}$ or $\left.n-\mathrm{C}_{4} \mathrm{H}_{8}\right)$ : These reactions were carried out following the same procedure as in (a) using $\mathrm{PdL}_{2}$ and an appropriate amine in iso-propanol. The products were recrystallised from chloroform. Yields, 70-95\%. The time required for the completion of the reaction when $\mathrm{R}=\mathrm{CH}_{3}, \mathrm{C}_{2} \mathrm{H}_{5}, n-\mathrm{C}_{3} \mathrm{H}_{7}$, and $n-\mathrm{C}_{4} \mathrm{H}_{9}$ was in the sequence of $3-4,2 \cdot 25-2 \cdot 55,1 \cdot 5-2 \cdot 2,1 \cdot 8$ and $1-2 \mathrm{hr}$., respectively as indicated by the dissolution of $\mathrm{PdL}_{2}$.

\subsection{Analyses}

Palladium in the complexes was estimated as its dimethylglyoximate, while copper was estimated iodometrically (Vogel 1951) after decomposing the complexes with a mixture of perchloric and sulphuric acids. $\mathrm{C}, \mathrm{H}$ and $\mathrm{N}$ were estimated by microanalytical methods.

\section{Results and discussion}

The results of the elemental analyses (not given) show that the metal: ligand ratio for all the complexes is $1: 2$. Pd(II) complexes are yellow, while those of $\mathrm{Cu}$ (II) show colours like red, brown and bluish green. In general, the complexes decompose 
above $200^{\circ} \mathrm{C}$. All the complexes except those with $\mathrm{R}=\mathrm{H}$, have good solubility in common organic solvents.

The complexes are non-electrolytes in acetone $\left(\Lambda_{M} \sim 2 \mathrm{Ohm}^{-1} \mathrm{~cm}^{2} \mathrm{~mole}^{-1}\right)$. The diamagnetism of the Pd(II) complexes suggests square-planar stereochemistry around metal, while those of $\mathrm{Cu}(\mathrm{II})$ are paramagnetic with $\mu_{\mathrm{eff}} \sim 1.90$ B.M., a value expected for the monomeric $\mathrm{Cu}$ (II) complexes without magnetic interaction. The molecular weights, as obtained from the mass spectra of $\operatorname{Pd}(\mathrm{IANI})_{2}, \operatorname{Pd}\left(\mathrm{C}_{2} \mathrm{H}_{5}-\mathrm{I}\right.$ $\mathrm{ANI})_{2}, \mathrm{Pd}(\mathrm{IAPI})_{2}, \mathrm{Pd}\left(n-\mathrm{C}_{3} \mathrm{H}_{7}-\mathrm{IAPI}\right)_{2}$ and $\mathrm{Pd}\left(\mathrm{C}_{2} \mathrm{H}_{5}-\mathrm{IBMI}\right)_{2}$ are respectively, 514, $570,542,626$ and 484, indicating their monomeric nature.

\subsection{Structure of $M L_{2}(R=H)$ complexes}

The ir spectra of $\mathrm{ML}_{2}$ complexes [M $=\mathrm{Cu}(\mathrm{II}), \mathrm{Pd}(\mathrm{II}) ; \mathrm{L}=\mathrm{IANI}$, IAPI] in nujol mull display an intense band in the region $1650-1670 \mathrm{~cm}^{-1}$ and a sharp band of medium intensity in the region $3320-3350 \mathrm{~cm}^{-1}$. These vibrational bands are assignable respectively, to the stretching frequencies of non-coordinated $\mathrm{CO}$ and coordinated NH. The occurrence of a single $\nu_{\mathrm{CO}}$ and a single $\nu_{\mathrm{NH}}$ is indicative of symmetric coordination of both the ligands as shown in IV and V.
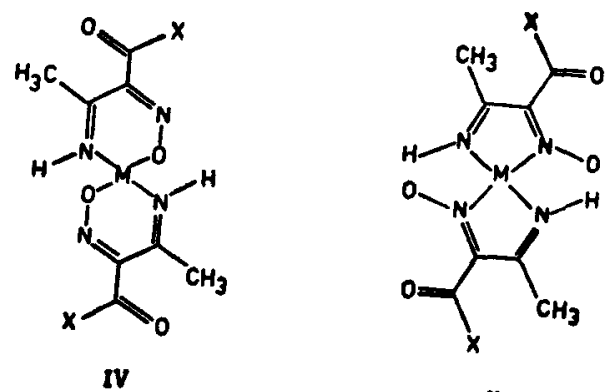

$v$

The positions of $\mathrm{CO}$ and $\mathrm{NH}$ vibrational bands which are significantly modified by the mode of coordination of the isonitroso group and the substituent $\mathrm{X}$ may be used as a probe to distinguish the chelate linkage isomeric structures IV and V. In $\mathrm{Ni}(\mathrm{II})$ (Lacey et al 1970; Bose 1970; Iyengar 1975; Iyengar et al 1975; Bose et al 1973) complexes of a series of isonitroso- $\beta$-ketoimines it has been rationalised that $\nu_{\text {co }}$ of isonitroso $\mathrm{N}$-bonded ligand appears at lower wave numbers than that of isonitroso O-bonded ligand and vice-versa for the coordinated $\nu_{\mathrm{NH}}$. In bis (isonitrosoacetoacetanilideimino) nickel(II) (Iyengar 1975), Ni(IANI)(IANI'), which is suggested to have an asymmetric structure, for example, $\nu_{\mathrm{CO}}$ and $\nu_{\mathrm{NH}}$ of O-bonded ligand (IANI') occur at 1683 and $3208 \mathrm{~cm}^{-1}$ respectively, while those of $\mathrm{N}$-bonded ligand (IANI) occur at 1669 and $3365 \mathrm{~cm}^{-1}$. The vibrational frequencies due to $\mathrm{CO}$ and $\mathrm{NH}$ observed in the present complexes are comparable with the isonitroso $\mathrm{N}$-bonded ligand of $\mathrm{Ni}(\mathrm{IANI})\left(\mathrm{IANI}^{\prime}\right)$. These results are consistent with the trans-symmetric structure $\mathrm{V}\left(\mathrm{X}=\mathrm{NHC}_{6} \mathrm{H}_{5}, \mathrm{NHC}_{6} \mathrm{H}_{4} \mathrm{CH}_{3}\right)$ for the present complexes. Furthermore, the complexes exhibit an intense band around $1200 \mathrm{~cm}^{-1}$,

*Abbreviations: IANI, IAPI, IPI and IBMI represent anions of isonitrosoacetoacetanilideimine, isonitrosoacetoacet-p-toludideimine, isonitrosopropiophenoneimine and isonitrosobenzylmethylketoimine and $\mathrm{R} \cdot \mathrm{L}$ denotes corresponding alkyl/aryl derivatives. 


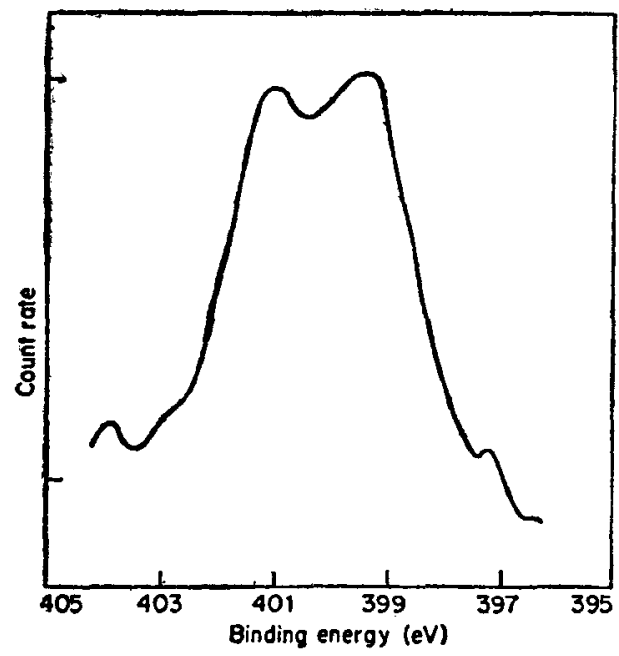

Figure 1. N 1s x-ray photoelectron spectrum of $\mathrm{Pd}(\mathrm{IBMI})_{2}$.

which is characteristic of coupled isonitroso N-bonded NO (Lacey et al 1970). This evidence also supports the symmetric structure. Structure of the type $V$ has been assigned for $\mathrm{Pd}(\mathrm{IBMI})_{2}$ and $\mathrm{Pd}(\mathrm{IPI})_{2}$. The ir spectra of these complexes show $\nu_{\mathrm{NH}}$ and $\nu_{\mathrm{NO}}$, respectively, around 3300 and $1150 \mathrm{~cm}^{-1}$. The position and shape of the $\nu_{\mathrm{NH}}$ band indicate the absence of H-bond.

The nitrogen 1s x-ray photoelectron spectrum of $\mathrm{Pd}(\mathrm{IBMI})_{2}$ (figure 1) shows two photoelectron peaks of almost equal intensities. The peaks at 399.4 and $401 \cdot 0 \mathrm{eV}$ have been assigned to azomethine nitrogen and isonitroso nitrogen coordinated to $\mathrm{Pd}(\mathrm{II})$, respectively. The binding energies are in excellent agreement with the coordinated nitrogens of isonitroso- $\beta$-ketoimine ligands (Swartz-private communication). These results also confirm the $\mathrm{Pd}-\mathrm{N}_{4}$ coordination in $\mathrm{Pd}(\mathrm{IBMI})_{2}$.

\subsection{Structure of $P d(R-L)_{2}$ complexes}

The ir pattern in the region $400-1800 \mathrm{~cm}^{-1}$ of $\mathrm{Pd}(\mathrm{R}-\mathrm{L})_{2}$ complexes $(\mathrm{R}=$ aklyl, aryl and $\mathrm{L}=\mathrm{IANI}$, IAPI) are similar to those of the corresponding $\mathrm{PdL}_{2}$ complexes, except for the absence of coordinated $v_{\mathrm{NH}}$ in the former complexes. The $\nu_{\mathrm{CO}}$ and $\nu_{\mathrm{NO}}$ in the complexes occur in the $1650-1670 \mathrm{~cm}^{-1}$ and $1150-1200 \mathrm{~cm}^{-1}$ regions respectively. These results indicate symmetric structure of the type $V$ for the present complexes. The structure of this type has been confirmed (Dixit et al 1977) by single crystal x-ray analysis for the molecule bis(N-ethyl isonitrosoacetylacetoneimino) palladium (II). $\operatorname{Pd}(R-L)_{2}$ complexes $(L=I B M I, I P I)$ are also suggested to have a similar structure. The characteristic isonitroso N-coordinated $\nu_{\text {No }}$ of these complexes appears in the $1145-1170 \mathrm{~cm}^{-1}$ region. The ir data indicate structure $\mathrm{V}$ for all $\mathrm{Cu}(\mathrm{R}-\mathrm{L})_{2}$ complexes.

The pmr spectral data of representative complexes are given in table 2 . The spectrum of $\mathrm{Pd}\left(\mathrm{C}_{2} \mathrm{H}_{5}-\mathrm{IANI}\right)_{2}$ shows only one set of proton signals due to $\mathrm{CH}_{3}$, $\mathrm{NHC}_{6} \mathrm{H}_{5}$ and $\mathrm{NHC}_{6} \mathrm{H}_{5}$ respectively, at 7.28, 2.50 and $-1.55 \tau$. The protons due to $>\mathrm{C}=\overline{\mathrm{N}}-\left(\mathrm{C}_{2} \mathrm{H}_{5}\right)$ moiety display a characteristic triplet and quartet pattern. Similarly 
Table 2. Proton magnetic resonance signals (in $\tau, \mathrm{ppm}$ ) of a few palladium (II) complexes along with their assignments*

\begin{tabular}{|c|c|c|c|c|c|c|}
\hline \multirow{2}{*}{ Complex } & \multirow{2}{*}{$-\mathrm{CH}_{3}$} & \multirow{2}{*}{$-\mathrm{C}_{6} \mathrm{H}_{5}$} & \multirow{2}{*}{$-\mathrm{NH}^{\mathrm{C}_{6} \mathrm{H}_{5}}$} & \multirow{2}{*}{$-\underline{\mathrm{NHC}_{6} \mathrm{H}_{5}}$} & \multicolumn{2}{|c|}{$\mathbf{N}-\mathbf{R}$} \\
\hline & & & & & $-\mathrm{CH}_{2}$ & $-\mathrm{CH}_{3}$ \\
\hline $\operatorname{Pd}\left(\mathrm{C}_{2} \mathrm{H}_{5}-\mathrm{IANI}\right)_{2}$ & $7 \cdot 28(s, 6)$ & & $2 \cdot 50(\mathrm{~m}, 10)$ & $-1 \cdot 55(\mathrm{~s}, 2)$ & $5 \cdot 97(q, 4)$ & $8 \cdot 78(t, 6)$ \\
\hline $\mathrm{Pd}\left(\mathrm{CH}_{3}-\mathrm{IBMI}\right)_{2}$ & $7 \cdot 94(s, 6)$ & $2 \cdot 74(\mathrm{~m}, 10)$ & & & & $6 \cdot 50(s, 6)$ \\
\hline $\operatorname{Pd}\left(\mathrm{C}_{2} \mathrm{H}_{5}-\mathrm{IBMI}\right)_{2}$ & $7 \cdot 97(\mathrm{~s}, 6)$ & $2 \cdot 67(\mathrm{~m}, 10)$ & & & $6 \cdot 02(q, 4)$ & $8 \cdot 84(t, 6)$ \\
\hline $\mathrm{Pd}\left(\mathrm{CH}_{3}-\mathrm{IPI}\right)_{2}$ & $8 \cdot 32(s, 6)$ & $2 \cdot 64(\mathrm{~m}, 10)$ & & & & $6.67(s, 6)$ \\
\hline $\operatorname{Pd}\left(\mathrm{C}_{2} \mathrm{H}_{5}-\mathrm{IPI}\right)_{2}$ & $8 \cdot 39(s, 6)$ & $2 \cdot 65(\mathrm{~m}, 10)$ & & & $6 \cdot 52(q, 4)$ & $8 \cdot 79(t, 6)$ \\
\hline
\end{tabular}

*Abbreviations: $s=$ singlet; $t=$ triplet, $q=$ quartet and $\mathrm{m}=$ multiplet. Integrated intensities and complexities of the signals are given in parenthesis.

the spectra of $\operatorname{Pd}(\mathrm{R}-\mathrm{IBMI})_{2}$ and $\mathrm{Pd}(\mathrm{R}-\mathrm{IPI})_{2}$, where $\mathrm{R}=\mathrm{CH}_{3}$ or $\mathrm{C}_{2} \mathrm{H}_{5}$, also exhibit single resonances due to $\mathrm{CH}_{3}$ and $\mathrm{C}_{6} \mathrm{H}_{5}$ of the chelate ring around 8.00 and $2 \cdot 70 \tau$, respectively.

The $\mathrm{N}$ is x-ray photoelectron spectra of $\mathrm{Pd}\left(\mathrm{C}_{2} \mathrm{H}_{5}-\mathrm{IPI}\right)_{2}$ and $\mathrm{Pd}\left(n-\mathrm{C}_{3} \mathrm{H}_{7}-\mathrm{IAPI}\right)_{2}$ show two peaks around 399.0 and $401.0 \mathrm{eV}$, which are assignable to coordinated azomethine nitrogen and isonitroso nitrogen, respectively. However, the intensity of the signal at $401.0 \mathrm{eV}$ in the spectrum of $\mathrm{Pd}\left(n-\mathrm{C}_{3} \mathrm{H}_{7}-\mathrm{IAPI}\right)_{2}$ is twice that of the lower energy peak. This suggests the merging of $\mathrm{N}$ ls signal of the nitrogen of $\mathrm{NHC}_{6} \mathrm{H}_{5}$ moiety with that of the isonitroso nitrogen. This observation may be ascribed to very small difference in their ionization potentials. The pmr as well as $\mathrm{N}$ ls spectral data coupled with ir data therefore, confirm the trans-symmetric structure with $\mathrm{Pd}-\mathrm{N}_{4}$ coordination sphere for all the di-alkyl complexes.

\subsection{Amine-exchange reactions of the complexes}

A large excess of amine is used in the preparation of $M(R-L)_{2}$ complexes by the reaction of $\mathrm{ML}_{2}$ with $\mathrm{R}-\mathrm{NH}_{2}$ (eq. 1). Qualitatively, the time required for the reaction (eq. 1) decreases in the order $\mathrm{CH}_{3}>\mathrm{C}_{2} \mathrm{H}_{5}>n-\mathrm{C}_{3} \mathrm{H}_{7}>i-\mathrm{C}_{3} \mathrm{H}_{7}>n-\mathrm{C}_{4} \mathrm{H}_{9}$. This sequence roughly corresponds to the reverse order of the basicities of the amines.

$$
\mathrm{ML}_{2}+\mathrm{R}-\mathrm{NH}_{2} \longrightarrow \mathrm{M}(\mathrm{R}-\mathrm{L})_{2}+\mathrm{NH}_{3}
$$

$\mathbf{M}=\mathbf{P d}(\mathrm{II}), \mathrm{Cu}(\mathrm{II}) ; \mathbf{R}=$ straight or branched chain alkyl.

These observations illustrate that in the present examples high concentration and basicities of the substituting amine are the driving forces of the amine-exchange reactions. These results are in agreement with those reported by Verter and Frost (1960) and Olzewski and Martin (1965) in their studiss on the amine-exchange reactions of bis(salicylaldimino) $\mathrm{Cu}$ (II).

In contrast to $\mathrm{PdL}_{2}$, the ligands in $\mathrm{CuL}_{2}$ do not undergo amine-exchange with isopropylamine. The difference in the reactions of $\mathrm{CuL}_{2}$ and $\mathrm{PdL}_{2}$ may be attributed to the steric hindrance between the protruding $>\mathrm{N}-\mathrm{O}$ and $>\mathrm{N}-\mathrm{R}$ in cis positions. This is expected due to the smaller size of $\mathrm{Cu}(\mathrm{II})(0.72 \dot{\mathrm{A}})$ as compared to that of $\mathrm{Pd}$ (II) (1.24 $\dot{A})$. However, $\mathrm{Pd}(\mathrm{II})$ complexes with $\mathrm{R}=i-\mathrm{C}_{4} \mathrm{H}_{9}$ could not be prepared by the 
amine-exchange reactions. This suggests that even in the case of $\mathrm{Pd}(\mathrm{II})$ complexes, steric factors are operative when $\mathbf{R}$ is sufficiently bulky. However, these complexes are obtained in low yields by the direct method.

A significant feature of the present studies is that the ligands coordinate symmetrically to the metal ions investigated, irrespective of the nature of substituents on the azomethine nitrogen (R) and carbonyl carbon (X). This is in contrast to isonitrosoacetylacetoneimine, which forms asymmetric complexes with Ni(II) (Bose 1970, Bose et al 1973) $\mathrm{Cu}(\mathrm{II})$ (Dixit et al 1976) and symmetric (Pd-N, N, N, N) as well as asymmertic (Pd-N, N, N, O) with $\mathrm{Pd}(\mathrm{II})$ (Bose et al 1973). Further, $\mathrm{N}$-alkyl isonitrosoacetylacetoneimine produces symmetric complexes with $\mathrm{Cu}$ (II) (Dixit et al 1976) and $\mathrm{Pd}$ (II) (Bose et al 1973) and such complexes are not formed by $\mathrm{Ni}(\mathrm{II})$.

Although, rationalization of the factors influencing the bifunctional coordination of the isonitroso group is difficult, it appears that the electron acceptor and/or donor properties of $\mathbf{X}$ and $\mathbf{R}$ dictate the mode of linkage of the isonitroso group.

\section{References}

Bose K S 1970 Ph.D. Thesis, Indian Institute of Science, Bangalore Bose K S, Sharma B C and Patel C C 1973 Inorg. Chem. 72720

Dixit N S, Bose K S and Patel C C 1976 Indian J. Chem. A14 507

Dixit N S, Manohar H and Patel C C J. Inorg. Nucl. Chem. Lett. (in press)

Hartung and Crossley 1943 Org. Syntheses Coll. Vol. 2363

Iyengar R R $1975 \mathrm{Ph} . \mathrm{D}$. Thesis, Indian Institute of Science, Bangalore

Iyengar R R, Bose K S and Patel C C 1975 J. Inorg. Nucl. Chem. 3775

Van L Knorr 1887 Ann. 23680

Kolb 1896 Ann. 291280

Lacey M J, Macdonald C G, Shannon T S and Collin P J 1970

Aust. J. Chem. 232279

McConnel J F, Lacey M J, Macdonald C G and Shannon T S 1973 Acta. Cryst. B29 2477

Olszewski E J and Martin D F 1965 J. Inorg. Nucl. Chem. 27345

Veter H S and Frost A E $1960 \mathrm{~J}$. Am. Chem. Soc. 8285

Vogel A I 1951 A text book of quantitative analysis (New York: Longmans-Green) II ed. p. 349

Sudha B P, Dixit N S and Patel C C 1975 Curr. Sci. 44651

Swartz W I private communication 